\title{
Changing lives and changing minds: the experiences of adoptive parents from application to approval
}

\author{
Cherilyn Dance and Elaine Farmer
}

\begin{abstract}
The recruitment and preparation of adoptive parents is currently high on the government's agenda with a number of far-reaching changes in policy, processes and guidance having been introduced in recent months. The fundamental aim of adoption from care remains as being the provision of, hopefully, stable and loving families for children whose parents cannot care for them but the experiences of adoptive parents in this process has recently moved from the wings to centre stage. This paper introduces the reflections of a group of adoptive parents ( $n=27$ ) about their experience of becoming adopters. The impact of delays in the process and experiences of the preparation and assessment period are discussed. A particular focus of the paper is on adopters' thoughts about the sorts of children they felt they could parent and how these changed in the course of their approval journey.
\end{abstract}

\section{Keywords}

Adoption, adopter preparation, adopter recruitment, matching, adopter preferences,

\section{Acknowledgements}

Many thanks to Caroline Thomas from the Department for Education for her support and assistance with this research. Funding for this study was provided by the Department for Education, for which we are very grateful. We would also like to thank Danielle Ouwejan who worked with us on this study as well as the adoptive parents and social workers who shared their experiences with us. 


\section{Word count 6,970}

\section{Changing lives and changing minds: the experiences of adoptive parents from application to approval}

\section{Introduction}

At a time when the recruitment, preparation and assessment of adopters is very high on the agenda in terms of the development of both policy and practice in England and Wales, it is appropriate to review recent evidence on the how these processes and rites of passage are experienced by adoptive parents in England.

The current government has laid considerable political store on the preparedness of families in local communities to provide for children whose birth families are unwilling or unable to raise them and over the past 18-24 months there has been a plethora of consultations, reviews and legislative changes in relation to adoption (see House of Lords, 2013 for a brief overview). Changes that are particularly relevant here include a new two-stage approval process for adopters and the expectation that assessment and approval will be completed in six months for the majority (Dept for Education, 2012). The outputs of these initiatives, taken together, issue a strong message which implies that successful recruitment of adopters (successful as in 'staying the course' through to approval and placement) is considered key to resolving the current imbalance between the number and characteristics of children waiting for a family and the supply of families able and willing to provide for their needs.

Social work practice in adoption has been under intense political and research scrutiny during this period too and the performance of local authority adoption agencies, in relation to efficiency of planning for children and processing adopter applications, is now routinely mapped on a number of indicators, with the findings made publicly available. Individual local authority adoption agencies are effectively 'named and shamed' in this process and improving practice in this area is a key objective for many. Chapter three of the recently published Statutory Guidance on adoption (Department for Education (DfE, 2013a, 2013b) places very clear expectations on local authorities with regard to the recruitment and assessment of adopters. These expectations include not just increasing recruitment and speeding up the process but ensuring that approved adopters are available and able to meet the needs of the children who need an adoptive family.

Whilst preparation for adoptive parenthood has long been considered an essential prerequisite and guidance on what should be included has been specified in broad terms (DfE, 2013), the precise format for that preparation has been left to agencies to decide. Good practice guides are available (Beesley et al., 2006; Romaine et al., 2007), but relatively few articles have focused on the way that adopters experience the pre-approval stage of the process or the ways in which their views change in the course of that process. Rushton and Monck (2009a) presented findings from their sample of adopters concerning levels of 
satisfaction with different elements of the preparation process. However, this study was specifically focused on an intervention for adopters who were experiencing difficulties and the finding that more help with managing challenging behaviour and attachment problems was high on the list of adopters' needs was not, therefore, surprising. This study did not examine motivations and aspirations. Ward's (2011) paper which examined the views of people responding to National Adoption Week identified changes in people's expectations and preferences about the sort of child they felt they could parent as they progressed through the adoption process, highlighting that whilst the majority of adopters are initially interested in young children, most are prepared to consider those who are somewhat older or children who need to be placed with siblings. However many have reservations about parenting children with disabilities.

This paper draws on one element of a large-scale study of family finding and matching in England to highlight issues that were identified by adopters as they progressed through the assessment and approval process and considers the ways in which preferences regarding child characteristics changed over time. It does so in an attempt to inform service development rather than further pillory practice.

\section{Research design and sample}

The data that form the focus of this paper are drawn from the second stage of a two part study focusing on family finding and matching in adoption. (Farmer and Dance et al 2010). Ten local authorities, representing a range of large counties, London and other metropolitan boroughs and unitary authorities, participated in this second stage of the study by identifying and referring cases to the research team where the recommendation was made that a child should be placed for adoption. One group of referrals to the study involved recommendations made in the past $(n=82)$, where data were taken from case files only. For the other group referrals were made in real-time $(n=67)$, that is as soon as those recommendations had been made, for this group both case file data and interview data were collected. Full detail of the sampling strategy and participation rates are to be found elsewhere (Author's own 2010). The focus here is on data provided by a small group of adoptive parents in the 'real-time' group $(n=27)$ who participated in face to face interviews about their experiences of applying, being prepared for and becoming, adoptive parents. These 27 families represent just over half of the 49 families matched with a child in this prospective 'real-time' element of the study.

\section{Ethics}

The development of the study was informed throughout by the involvement of reference groups of adoptive parents, adopted children and service providers - as well as an advisory group. The proposed research was approved by the Ethics Committee of the University of Bristol and by the Association of Directors of Social Services (ADSS) (now the Association of Directors of Children's Services). In addition, permission to review documents on adoption files was given by the Department for Constitutional Affairs (DCA now the Ministry of 
Justice) and the Secretary of State. Approval from the research governance committees of individual local authorities was also obtained.

The principles of informed consent, anonymity and confidentiality were observed throughout, although all participants were made aware of our duty to breach confidentiality in the event of a disclosure of significant harm. For the real time group many of the files were read prior to the identification of adoptive families but where families had been identified we sought, and obtained, their direct consent for the file to be read.

\section{Methods}

Methods relevant to the analyses presented here include some of our case-file review data and the adopter interviews. For the case-file review a range of data were extracted from the files for all children ( $n=149$ ) onto a largely pre-coded proforma with space available for as much qualifying and explanatory commentary as needed. The child's case file following placement included a copy of the Form F or PAR and from this information about families' characteristics and preferences in terms of the sort of child they were approved for was taken.

Two study specific interview schedules were designed for use with adoptive parents: one which was used at the first interview point shortly after the match with the child had been agreed and the second for use at follow up six months later. The interviews included a mix of open and closed (pre-coded) questions designed to explore adopters' expectations, experiences and views about the adoption process (first interview) and about the placement (second interview). However, it is the experiences of adopters in the pre-placement stage that is the concern here, and specifically their experiences of preparation and assessment, with a particular focus on how their views might or might not have changed in the course of this period.

Quantitative data arising from interviews were managed using SPSS v17. In this paper quantitative data are provided to describe the sample and the pattern of responses to closed questions. Interviews were transcribed and the qualitative data were analysed using NVivo 9 (a software package) which assisted in the organising, coding and cross-referencing of data. The aim of the analysis of qualitative data was to explore the range of experience in the early stages of the journey to adoptive parenthood and to draw from the narratives key themes and messages with relevance to practice. Thus responses relating to each aspect of the application and approval process were read and passages were coded and categorised according to experience in the different stages. Rather than focusing on solely on themes, the remainder of this paper combines responses to closed interview questions and explores adopters' views and experience in each phase of their journeys.

\section{The start of the journey to adoption for adoptive parents}


Only limited information on the experiences of adoptive families was available in the children's case files so we had to rely on the interview group to explore the precursors to the match from the parents' points of view. Most of the families we spoke to were heterosexual couples where the female partner would become the primary carer for the child/ren. We explored with participants the beginnings of their thinking about adoption. The majority reported that they had started to think about creating or enlarging their family through adoption a long time before they made their first moves to do so. Indeed the mean period of time between first thinking about adoption and the placement of their adopted child was around five years (ranging from 18 months to about 15 years). In talking about this topic, it became clear that there were a number of adoptive parents who had existing connections with adoption or fostering who had always felt that they would like to adopt, regardless of whether they had their own birth children. For other families, adoption was something that they had only begun to consider when they discovered their infertility. We asked parents what had actually triggered their first moves towards adoption: what made them pick up the phone or send an email. For most (16 of $27,60 \%$ ), there was no specific trigger, simply that the time was right for them to make enquiries:

\section{No [we didn't see an advert or anything]. Interestingly it was funny because once we actually started [the application process] we started seeing stuff everywhere didn't we? So I don't know if it was just that we hadn't really been [looking]. And we chatted to a load people [and discovered] that they were either going through it or they know people who are. I don't know if it was just that we weren't looking for those sort of adverts do you know what I mean, you know, sometimes when it doesn't seem relevant, you don't take notice, do you?}

A few people mentioned that advertisements by agencies in newspapers or other magazine articles had proved a 'spur' to action and one mentioned 'National Adoption Week', although in all cases adoption was something they were already thinking about. Other factors were also mentioned, for example the publicity around the change in the law concerning discrimination which some felt would mean their applications might be taken more seriously. In 16 of the 27 parent interviews, the initial idea of adoption was described as being an idea shared between couples (where applicable). In the majority of the remaining cases it was the adoptive mother who initiated the discussions.

\section{The preparation and assessment phase}

The journey through the preparation and assessment period was experienced differently by different people. The descriptions given by the parents about this period showed that the majority had found it a primarily positive experience but that it was at best 'mixed' or at worst 'difficult' for two fifths (11 of 26 families, 42\%). Even amongst those who were positive there were lots of phrases like 'intense', 'difficult', 'emotional' but these were 
countered with words such as 'confirming', 'interesting' and 'rewarding'. With the other two groups there was more mention of frustrations and upset. Although those who described their assessment period as a 'difficult' experience had all encountered delays in the process, there was no direct relationship here: by no means had all those whose progress was delayed felt that the assessment had been difficult.

The majority of adoptive parents felt that they had learned a lot from the group preparation courses that they had attended, although there was some criticism of the volume of material that was presented - and how emotionally draining and tiring it could be. A few had quite strong views on certain aspects of the group preparation: with some expressions of discomfort, particularly with the group work and role play:

Another thing is that they expect you to do things that you don't feel comfortable with, like I don't deal very well in crowds of people, having to stand up and perform in front of people. I don't deal with that very well. But they were asking me to do that. And we had to get into groups and be like a spokesman of it and it was just, it was very, it was hard for me, I didn't like it at all.

To some extent this may be about different people's preferences and sensitivities but equally it might be how individual courses are run. Another parent felt quite differently about it:

I mean the courses were always.... you never felt pressurised into doing something wrong, you know, sometimes you can go to these things and you think, 'Oh God, I'm on show all the time or we're going to be ticked down if we laugh at something we shouldn't laugh at' - but not at all.

Even for those who were used to group work activities in their professional roles, there were additional challenges in the preparation courses for adoptive parenthood:

I found them hard going at times. I enjoyed them, it was okay, but I found... I'd been in [my job] for 25 years and in 25 years you do loads and loads of group work and talk about feelings and all that. Sort of like sit in a circle and "How do you feel about this"? And I'd sailed through all [of that] but this, because it was so close and it was talking about your emotions, how you feel - I found it difficult, I found it challenging. I thought that I could just sort of sail through it but, no, it was quite a challenge.

Universally appreciated was the input of adoptive parents and some felt that more could be made of this - particularly perhaps around the impact of the process:

I think just perhaps more of someone [an adopter] just sitting there saying, "Really, this is really how it's going to be and this is really how you're going to feel - and you're going to walk out of here totally confused". 
A fairly common comment when discussing preparation groups concerned the focus on 'horror stories'. Parents understood that there needed to be some discussion of what might be difficult or might go wrong but many had developed their own theories as to why there was such a concentration on this area:

But we actually went in thinking, quite open minded, that we're going to get the worst case scenarios and if you can make it through this then you're going to be serious which is good. I think they do need to have the horror stories, but on the other side of it they also need to tell you a bit of the joys, because I think there's too much scaremongering with people.

There was no suggestion in the data that the assessment period was more difficult for families where one prospective adopter was keener than the other. In this sample, some of those who already had children mentioned particular difficulties with the preparation process:

... We were different in lots of variables compared to I would guess what most people are like, and much of the collateral and much of the discussion centred on essentially couples, typically younger than us, who hadn't conceived a birth child. So we're old and kind of over the top as to striving to do OK in our lives, with a birth child. Not that anything made us feel bad or different, it's just we felt it.

Prospective adopters were also grateful for the opportunity to meet other people in the same situation and they sometimes provided a considerable amount of mutual support during the preparation period. For one participant the value in the preparation groups was the opportunity to meet with others who had been through the experience of fertility treatment. However while friendships sometimes continued, for others there were difficulties in keeping relationships going after approval as people's passage through to placement moved at different speeds:

I think probably what has happened is everyone's got a bit uneasy .... you don't really want to email everyone... You don't know whether some people have a delay, some people are waiting, some people have dropped out and I think everyone's got a bit uneasy about that.

Recollections of the home study period were usually fairly positive, although delays and frustrations, sometimes associated with specific workers, were evident. People did find the process intrusive, not surprisingly, but understood why it needed to be done. What was of great concern, where it occurred, were errors and inaccuracies in the paperwork, and insufficient time to make changes when workers had left things too close to deadlines. One adoptive parent said: 
Oh a lot of the stuff was, she could write down, things that she felt, well presumably this is the case, [but] she was writing down stuff that we didn't say but she thought would hold us in good stead when we went to panel. Occasionally she'd hit the nail on the head, but quite a lot of the time the things that she started to say about us, were not us. So I think there's a lot to be learnt in terms of how to write a Form F really well. It can't be easy.

And another adopter commented:

So what definitely comes to mind, which is a by product of it dragging on, is that there was work we'd spent hours on, [and] she'd [our social worker] lost it - it's like come on!. Just as an aside, our Form F, with the financial statement and everything, got lost in the post. Our deepest personal details went missing...The paperwork we were asked to sign was a photocopy of somebody else's personal details, we had somebody else's personal details on our form

These concerns about the accuracy and security of personal details were voiced relatively rarely, certainly not to the extent suggested by the quotations above, but they are worrying - especially when set alongside the fact that there were also a substantial number of errors and misfiling in relation to children's details. This was both reported to us by adoptive parents and directly evident in the paperwork that we examined when reviewing case files.

\section{The length of the journey}

For the majority of families, even ignoring the thinking time that preceded their formal enquiries, the period between application and placement was extensive. Almost half of the parents we spoke to reported unexpected delays in the course of their preparation or home study period. The mean time between application and placement for the 27 families was 26 months (mode 23, range 15-48, sd=9.6). Times between application and approval ranged from five to 28 months (mean 16) and the period between being approved as adopters and the child being placed ran from almost no time (in the case of approval and match being recommended at the same time) to 36 months of waiting (mean 9.7 months). It can be seen then that the experiences of participating adoptive parents had been very varied. For some, parts of the process must have been like a whirlwind, while for others there had clearly been tremendous frustration and anxiety that time was slipping by.

Delay could occur for prospective adopters at all points of the journey. Their initial enquiry might be timed so that they missed one open evening and had to wait until the next before they could proceed. Delays in getting medical or other paperwork might mean that they missed the next available preparation group. Depending on the frequency with which open evenings and preparation courses occurred within individual authorities, missing these deadlines could add significant periods of 'non-progress'. The home study, once a social 
worker had been allocated, could be delayed for a variety of reasons and actually getting to panel was dependent on the paperwork being properly prepared and the availability of a slot in the panel's agenda.

Clearly a process in which progress is dependent on the successful negotiation of so many 'checkpoints' is vulnerable to delay. Those we spoke to, who missed deadlines early in the process, felt their involvement in the adoption process to be much extended. Where more than one of these potential difficulties had occurred, people expressed tremendous frustration - especially when, as illustrated in the quote below, a potential match was then proposed in almost no time at all:

We indicated our desire to adopt [just over two years ago] and it took until [just 4 months ago] to get to [approval] panel and then literally a handful of weeks after ratification - up pops [our son].

\section{The views and preferences of adoptive parents and how these developed and changed}

Our main interest in exploring the preparation and assessment experience with families was to be able to explore with them the extent to which their views had changed in terms of the sorts of child characteristics that they thought they could manage (see also [Author's own, submitted). There has been a lot of discussion in the literature about 'stretching' of adopters' 'preferences' with regard to the age groups or the sorts of problems that children might have which people feel they can manage (Barth and Berry 1988, Berry 1997, Nelson, 1985). Our impressions from reading the case files in the larger study were that, for the most part, where matched children had particular characteristics or problems, these were issues that the families involved had always felt able to deal with. There were just 11 of 99 cases (where data were available) (11\%) where there was evidence on file of a shift in new parents' willingness to consider specific problems (Author's own, 2010). That said, all of the papers that we were reading were papers that had been prepared subsequent to lengthy discussions between applicants and assessing social workers (in the case of the Form F/Prospective Adopters Report) or with the needs of a particular child in mind (when thinking about the Adoption Placement Report - the APR). It is possible that recorded detail about these issues might have been found in the assessment records kept on the adopters' file.

In contrast, from speaking to the interview group, we learned that for nearly two-thirds of parents their views about the sort of child they were expecting to parent had changed in the course of the preparation, assessment or waiting period, sometimes many times. For the most part these changes concerned children's ages or the number of children they felt they could parent, although there was also some discussion about levels and types of disability or behavioural issues. 
Sometimes parents actually found it quite difficult to answer this question about changes in preferences because it depends where one starts.

But [discussions during home study] did help us crystallize the kind of decisions we would have to be making when we got to the selection and the matching kind of process, so did it change us ...? I'm not sure if it changed us because I'm not sure where we started from, because we had a kind of general view of ... we always had a notion that we wanted a family and that we weren't trying to save the world or save any children.

In reality the implication of the phrase 'stretching of preferences' is very difficult to define and to pin down when and how this might occur. In some ways people can be clear about things they feel unable to manage, but in the real world this is balanced against their desire to parent a child by adoption. It seems likely that the character and intensity of that need or desire is coupled with people's understanding of the characteristics of children who need an adoptive family and their own perceptions of their 'ranking' in terms of desirable parent characteristics (such as their ages, ethnicities or family composition for example).

The way in which these areas were discussed by adoptive parents makes it clear that very often their views were based on perceived 'availability' of children rather than their preferences. Many people talked about how it was 'natural' to really want a baby, as young and as healthy as possible. On learning that this was considered extremely unlikely, for most there was an automatic re-think - which usually happened very early in scheme of things. One adoptive parent said:

Because we always knew that we'd quite like a little one, we never thought we would, because everybody said there's a shortage of babies....This is what they said the first day of the [preparation] course, they said "You know if you're expecting to get a blue eyed baby, [you're not] going to get a blue eyed baby.".... [In fact] we are getting a blue eyed baby, blond haired, blue eyed baby - yes we're getting a very blue eyed baby.

Another commented:

Well it changed basically because we were told by our agency that if we wanted a baby, our best bet would be to take two and we'd be more likely to get a young one that way. So we thought "Okay fine", you know, we've always wanted more than one so fine we'll take two. And it was really at the last knockings, when we had our, what's called 'second opinion' visit, when your social worker's boss comes to see you just before the panel report is put together (to check that you haven't been bribing your social worker to say nice things). And she said "Would you consider one?" Well why? She said "Well you're more likely to get a young 
one if you take one". We thought "Oh, hang on a minute, that's completely the opposite from what we've been told for the last however many months".

Such a dramatic change in direction, so late in the day, must have been quite difficult for these parents to deal with: having had, presumably, all the discussions with family members and friends, planning their environment and preparing themselves to parent two children.

This couple went on to discuss how, with hindsight, they were very glad that they had changed to just one. In fact their child was placed just after his first birthday and the couple talked openly about how, having experienced caring for one child, they did not feel they would have wished to cope with two placed simultaneously.

The issue of 'how many children' was live for a number of the parents we spoke to: some had entered into the process anticipating adopting a sibling group:

Well before we started the assessment we both were thinking of adopting two siblings. I was more convinced than my husband actually. And then when [the adoption worker] started doing, well we started doing the match with children, she said more or less, she didn't convince me but she said that it would be... I still want another but we'll wait for a bit.

Here there is the sense that discussions with the adoption worker had impacted on this parent's initial expectations. And again:

Yes, we were thinking about sibling groups because we wanted them to have brothers and sisters and for us to have a family unit. You know, that was always the plan, wasn't it? And I think we'd also, it was all quite unrealistic in that we weren't thinking, you know, our ideal family would have been to have a large family, that was the plan, and so we were like, "Well three would be great". What you fail to realise is there are three children who come instantly and that's not how families are made.

This interviewee did not go on to clarify what had influenced her thinking in this regard but this couple did go on to be matched with one young child. One couple had initially been approved for a sibling group of two or three but they realised that this had resulted in them being overlooked for the smaller groups because of their potential value in having been approved for three children.

Another couple also drew attention to what they learned in the process of discussing 'preferences' with their social worker. They perceived that they were particularly valued for their vocational experience with school age children and having demonstrated an ability to deal with some level of emotional and behavioural problems. Implicit in their words, however, is the sense that this was not necessarily how they wanted to see themselves as parents. 
So whatever you said on your Form $F$ (or whatever) becomes a bit different when you're faced with children as to whether you think you can really cope with this, that or whatever. And also we learned a lot about how we were viewed by social workers as well at that time, didn't we? We were viewed very positively, but we were viewed very positively in regard to our ability to deal with certain things. Yes, probably we do come across as very able to deal with those things .... behavioural issues and children with sexual abuse and things like that. And, you know, we probably would be fine-ish with those things but I think in reality, if we were faced with children like that, we would find that more difficult than what we are dealing with.

People also drew attention to how hard it was to think through, in the abstract, and be sure about what they could and could not cope with - and this was particularly evident in relation to considering children who had disabilities or health conditions:

Parts of it helped us crystallize the type of child we might adopt because we pushed quite hard on levels of disability for example, that sort of thing and background, you know what sort of child. We wrestled with that for a while because it was so hard because it was the notion that we couldn't do that in the abstract it was ... if there was a child and their name was Fred and they have $X, Y$ and $Z$ attributes then that is easier than just going "Would you be able to accept a child who had Cerebral Palsy or something?" It is hard to do it in the abstract.

Nonetheless, there were some prospective adopters who changed their idea of the child they wished to care for quite radically and this was especially likely with 'adopter-led' matches. This phrase is used here as shorthand for those matches that came about as a result of prospective adopters responding to information about children who needed a family. In such cases people talked about being drawn to a child or children outside the age range they had planned on or those with greater problems than they had originally wished to consider as a result of seeing video or other material about the child/ren. For example, one couple described how they had originally wanted a baby but ultimately adopted a 7 year old girl who they had seen at a video-profiling event:

Initially we were, you know, we wanted a baby just so we could see a baby growing up, and a boy was, you know, [our birth child] was a boy we know what boys do, we know what boys are... and so that's the way we were thinking. But we went to [a meeting for prospective adopters to see video profiles of children and meet their social workers], and we saw [a 7 year old girl] needing a family. And we just saw her and said, "That's our daughter," in many more ways than just, you know, we liked the fact that she did this or did that, or she was like this or she was like that, you know. We saw her and she looked liked [our son's] cousin... 
In a similar way, one single woman had initially wanted a child without any physical disability and did not want a child needing a lot of support but was attracted at a profiling evening to a child with severe gross motor delay who needed a lot of support and the child was successfully placed with her.

So in summary, for many families there seemed to be a good deal of movement with regard to people's expectations from the point of first thinking about adoption. Sometimes this seemed to occur spontaneously in response to people's understanding of the profile of children needing families and their perception of how 'desirable' their family was - or through their exposure to profiles of children who needed a family. However, there was also evidence, in some cases, of practitioners influencing people's choices. There were other parents though, 11 of those interviewed, who did not feel that their views had changed: One family went so far as to say:

No, we always said 'under twelve months'. And it was very clear right from day one what we wanted: we wanted the most uncomplicated, under twelve months old child that was possible on this planet - and that's what we've got.

\section{Summary and implications}

This paper is based on the responses of a relatively small group of adopters and may therefore not be representative of the views of all adopters. It is also the case that whilst recruitment and preparation were important aspects of the larger study they were not the main focus and the time devoted to it during interviews was relatively brief. Nevertheless this exploration of the experiences of adoptive families as they progressed through the first stages of the adoption process has highlighted several important issues that relate directly to practice and procedures as implemented within agencies. These are things that can, therefore, be fairly readily addressed and need to be borne in mind as agencies are reframing their approach to adopter recruitment and assessment in line with the new statutory guidelines.

We began the discussion of our findings exploring adopters' experiences of preparation groups. Much of what they had to say has been reported previously but has been so either in the context of it being a small part of a much larger study (Quinton et al., 1998) or the focus has been on particular programmes of preparation (Farber et al., 2003; Rushton and Monck, 2009b). To date there is relatively little that puts general feedback in the public domain.

One of the relevant observations to be drawn out is the fact that for the majority of parents we spoke to there was no particular trigger that prompted their making enquiries about adoption - it was simply that the time was right for them. This underlines the need for 
recruitment services to be responsive at all times and not overly focused on gearing up to respond to recruitment drives.

Of particular note in our findings is that the group preparation was generally well received: most people reported learning a lot from it, although the majority of interviews took place before the child had been placed. The opportunities the groups offered to meet others going through similar experiences were valued, although friendships made did not always sustain because of worries about people's different rates of progress towards placement. People did highlight though, how physically and, more importantly emotionally, draining it could be: there was tangible shock evident in the words of some participants when they described some of the materials and information that they were exposed to, although it was appreciated that this was essential learning experience. In a similar vein, some people were very uncomfortable with role play exercises or discussing their deeply personal feelings in public - both of these issues suggest that care is needed to ensure that people understand why they are being asked to put themselves through these experiences. Input from people who had themselves adopted was highly valued and it was suggested that more of this would be useful. Particularly important was reassurance that feeling overwhelmed and confused was OK. Many felt that the 'horror stories' were overplayed and came to see the groups as something of a survival course: Some balance would have been appreciated. Finally the needs of people who have parented before were not always sufficiently taken into consideration.

The learning from adopters' discussions of the home study suggests that much depends on the skills and experience of the assessing social worker in terms of how this is experienced and for many people it was described positively. However, there were delays in allocation and in completion of this stage and worryingly there were occasional issues about the accuracy of recording on the PAR and security of information.

We included in our presentation of findings a brief discussion of delays and issues in the process of preparation and approval for adoptive parents. This is very much the focus of the most recent round of legislative and policy initiatives. For a number of parents in our study the progress from application to approval was very slow, indeed the average time was 18 , rather than the recommended six, months (see also Adoption UK, 2011). Our data however revealed that delays for potential adopters in the pre-approval stage can occur at a number of points and often for purely practical reasons. Processes need to be made more flexible and responsive while still recognising that some people might need more time.

In thinking about adopter preferences and expectations, it is obviously important to encourage prospective adopters to be realistic about the sorts of children who need adoptive homes but the strength of the current message to prospective adopters about the scarcity of babies might benefit from being somewhat modified. Although not reported in full here, our study found that one third of the children in our sample had never lived with their birth families, indeed many of these had entered care at under a week old and one in 
five had a recommendation for adoption before they were six months old (and that was in a sample that was skewed to over-sample on older children and those with complex matching needs).

Equally we have recounted how the experience of some of our participating adopters had been that their initial aspiration to parent a sibling group altered in the course of their home-study, such that they ended up being approved for just one, or possibly two, children. We have no way of knowing for sure why people adjusted their expectations or how frequently it may occur. It is possible that adoption workers' efforts to encourage adopters to be realistic about their abilities and their resources result in parents 'playing safe'. Nevertheless, it does suggest that this may be contributing to a tension in practice between the desire to place siblings together (unless there is good reason not to) and the extent to which prospective adopters are encouraged to consider their ability to parent siblings. This is particularly true at a time when there is pressure on agencies to place children speedily and decision making about sibling separation can be a factor in delay in individual cases ([Author's own 2010). It is worth opening up the debate about how we might best assist adopters who do wish to parent a larger family. Saunders and Selwyn's recent work with people who adopted large sibling groups demonstrates that some adopters can manage this task - although support is needed (Adoption Expert Working Group, 2012; Saunders and Selwyn, 2012). With this in mind, it is interesting to note that adoptive parents did not spontaneously mention support in their reflections on these early stages of the process.

Overall, changes in people's views about the sort of children they felt able to parent were observed in about 60 percent of cases, these changes occurred through both increased understanding about the needs of children waiting for adoption and through discussions with practitioners. Participants did highlight, however, how difficult it was to think about these issues in the abstract. Cousins (2003) has argued that the hypothetical approach of asking about the kind of child people would be prepared to adopt may create barriers to finding appropriate families for children since it is when adopters face a real child at the linking stage that they are better able to identify how they feel about becoming that child's parents and as a result they may move beyond their original preferences. In support of this, some very significant shifts were seen to occur in adopter-led placements in the study reported here.

The recent changes in policy and the accompanying statutory guidance on the adoption of looked after children have clarified the expected time-scales for the approval process for potential adopters as well as providing for a two-stage process that establishes preliminary suitability to adopt at an early stage (DfE, 2013a). This should mean that fewer adopters face the frustrations experienced by some of the participants in this study. However, because the focus is, rightly, on the best interests of the child, relatively little is said about how prospective adopters are to be supported and their interests promoted once they have 
been approved. That said, the provisions for the adoption passport and the ability to selfrefer to the Adoption Register should provide adopters with more autonomy in the process.

\section{References}

Adoption Expert Working Group (2012) Redesigning Adoption. Available at: www.gov.uk/government/uploads/system/uploads/attachment data/file/180251/w orking groups report on redesigning adoption.pdf (accessed 12 August 2013).

Adoption UK (2011) Waiting to be parents: adopters' experiences of being recruited. Banbury: Adoption UK.

Beesley P, Hutchinson B, Millar I and de Sousa S, (2006) Preparing to Adopt: A training pack for preparation groups. London: BAAF.

Cousins, J. (2003) Are we missing the match? Rethinking adopter assessment and child profiling, Adoption and Fostering, 27(4): 7-18

Department for Education (2012) An action plan for adoption: tackling delay. www.education.gov.uk/publications/eOrderingDownload/action\%20plan\%20for\%20 adoption.pdf (accessed 12 August 2013).

Department for Education (2013a) Statutory Guidance on Adoption For local authorities, voluntary adoption agencies and adoption support agencies. London: Department for Education. July 2013. Reference: DFE-00126-2013. Available at: http://media.education.gov.uk/assets/files/pdf/s/adoption\%20statutory\%20guidance\%2020 13\%20final\%20version.pdf (accessed 12 August 2013)

Department for Education (2013b) Further Action on Adoption: Finding More Loving Homes. London: Department for Education. January 2013. Reference: DFE-00003-2013. Available at: https://www.gov.uk/government/uploads/system/uploads/attachment data/file/219661/F urther 20Action 20on 20Adoption.pdf. Accessed 12 August 2013)

Farber MLZ, Timberlake E, Mudd H P and Cullen, L (2003) Preparing Parents for Adoption: An Agency Experience. Child \& Adolescent Social Work Journal 20 (3): 175-196.

Farmer E. and Dance C. with Beecham J., Bonin E. and Ouwejan D. (2010) An Investigation of Family Finding and Matching in Adoption, Report to the Department for Children, Schools and Families, School for Policy Studies, University of Bristol

House of Lords Select Committee on Adoption Legislation (2013) Adoption: Post-Legislative Scrutiny. London: The Stationery Office Limited. Available at: http://www.publications.parliament.uk/pa/ld201213/ldselect/ldadopt/127/127.pdf (accessed 12 August 2013)

Rushton A and Monck E (2009a) Adopters' experiences of preparation to parent children with serious difficulties. Adoption \& Fostering, 33 (2): 4-12

Rushton A and Monck E (2009b) Enhancing Adoptive Parenting: A Test of Effectiveness. London: BAAF. 
Romaine M, Turley T and Tuckey N (2007) Preparing children for permanence--A guide to undertaking direct work for social workers, foster carers and adoptive parents. London: BAAF.

Selwyn J and Saunders H (2011) Adopting Large Sibling Groups. London: BAAF

Ward E (2011) Taking the Next Step: Enquirers to National Adoption Week One Year on. Adoption and Fostering 35 (6): 6-17 